\title{
Bronchial Carcinoma Treated with Nitrogen Mustard and Cyclophosphamide
}

\author{
KATHARINE M. BARRAN,* M.B., CH.B.; W. H. HELM,† M.R.C.P.; D. A. KING, $\ddagger$ M.R.C.P.ED.
}

Brit. med. F., 1965, 2, 685-687

Nitrogen mustard (mustine hydrochloride) has been used in the treatment of lung cancer for 20 years. Lynch, Ware, and Gaensler (1950), Kent and Reh (1950), Levine and Weisberger (1955), Hatch, Bradford, and Ochsner (1956), and Bass (1960) have described their experience with this cytotoxic agent and have reported symptomatic improvement in many patients, but little or no prolongation of life. Since 1958, when cyclophosphamide was synthesized, it has been widely used for malignant disease, including lung cancer, both palliatively in advanced inoperable disease (Spear and Patno, 1962 ; Braun-Wotke, 1963), and as cover for operation in patients with less-advanced disease (Poulsen, 1962, 1963).

\section{Present Investigation}

Our primary aim was to assess the objective evidence of improvement in patients with bronchial carcinoma treated with nitrogen mustard and cyclophosphamide and to compare the results of the two agents. The secondary aim was to assess the effect of early " follow-up " treatment on the survival time in the patients who had improved.

Selection of Patients.-The series ran for two years. At first all patients presenting with bronchial carcinoma at two chest clinics were included. After a short time patients who were suitable for operation were excluded because it was feared that cytotoxic therapy might be lowering the pulmonary diffusing capacity. Later investigations did not confirm this suspicion. There were 88 men and 9 women, and alternate male patients were given nitrogen mustard and cyclophosphamide, except at one peripheral hospital where it was difficult to manage intravenous nitrogen-mustard drips and all five male patients had cyclophosphamide. All female patients had nitrogen mustard.

Diagnosis.-In 36 out of the 48 patients treated with nitrogen mustard and in 37 out of the 49 having cyclophosphamide, histological proof of neoplasm was obtained. In the remaining 24 the course of events gave strong support to the diagnosis.

Routine of Treatment.-All patients in both groups had Durabolin (nandrolone phenylpropionate), $50 \mathrm{mg}$. intramuscularly once a week, and prednisone, $20 \mathrm{mg}$. daily, in an attempt to safeguard the bone-marrow. White-cell counts were carried out on alternate days during treatment and for a few days after the course, and at one hospital platelet counts were also carried out on alternate days. Patients on nitrogen mustard had $10 \mathrm{mg}$. on alternate days for four doses given into a fastrunning normal saline drip. Patients on cyclophosphamide had a test dose of $200 \mathrm{mg}$. intravenously, followed by daily doses of $400 \mathrm{mg}$. up to a total of $5 \mathrm{~g}$., except where marked bonemarrow depression occurred.

Assessment of Results.-The results have been assessed entirely on the objective evidence available, and subjective improvement has not been taken into account. Objective evidence has consisted of $x$-ray changes and resolution of

\footnotetext{
* Chest Physician, Scotton Banks Hospital, Knaresborough. † Consultant Physician, Scotton Banks Hospital, Knaresborough. ‡ Formerly Medical Registrar, Scotton Banks Hospital.
}

palpable secondary glands, palpable masses, and signs of mediastinal and vena caval obstruction. In patients with a bronchoscopic abnormality before treatment and in whom the $x$-ray changes with treatment were indefinite a second bronchoscopic examination was carried out before the assessment was made. In 9 out of 19 of these patients marked bronchoscopic evidence of improvement was found.

"Follow-up" Treatment.-All patients who improved, with the exception of four who underwent resection, were allocated in sequence to one of the three "follow-up" treatment groups: (1) deep $x$-ray therapy with linear accelerator; (2) further intravenous injections of $1 \mathrm{~g}$. of cyclophosphamide or $15 \mathrm{mg}$. of nitrogen mustard in a single dose ; or (3) pulmonary-artery perfusion with the same cytotoxic agent as previously-15 mg. of nitrogen mustard or $1 \mathrm{~g}$. of cyclophosphamide in $150 \mathrm{ml}$. of normal saline dripped over half an hour. Preliminary pulmonary-artery angiograms were carried out in these patients and only those with patent pulmonary-artery trees were perfused; others were included in the intravenous or deep $x$-ray therapy groups (three had evidence of arterial block).

\section{Results of Treatment}

There was objective evidence of improvement in $25(51 \%)$ out of 49 patients treated with cyclophosphamide and in 16 $(33 \%)$ out of 48 treated with nitrogen mustard (Table I). This difference, although suggestive of a greater benefit from cyclophosphamide, does not reach the $5 \%$ level of significance $\left(\chi^{2}=2.45\right)$. The dosage was probably not entirely comparable, as a greater fall in the white blood count tended to occur on the cyclophosphamide regimen than with the nitrogen mustard (Table II) and a larger dose of the latter might well have been tolerated, with an increase in the number of favourable responses.

TABLE I.-Histology and Objective Improvement

\begin{tabular}{|c|c|c|c|c|c|}
\hline & & \multicolumn{2}{|c|}{ Nitrogen Mustard } & \multicolumn{2}{|c|}{ Cyclophosphamide } \\
\hline & & Total & Improved & Total & Improved \\
\hline $\begin{array}{l}\text { Squamous cell .. } \\
\text { Oat cell ... } \\
\text { Undifferentiated } \\
\text { Adenocarcinoma } \\
\text { Carcinoma-in-situ } \\
\text { Carcinoid -in- } \\
\text { No histology }\end{array}$ & $\begin{array}{l}.: \\
\because \\
\because \\
.\end{array}$ & $\begin{array}{r}15 \\
7 \\
11 \\
2 \\
\frac{1}{12} \\
12\end{array}$ & $\begin{array}{c}3_{3}^{3}(20 \% \\
5\}(44 \%) \\
= \\
5 \overline{(42} \%)\end{array}$ & $\begin{array}{r}15 \\
7 \\
11 \\
3 \\
1 \\
12\end{array}$ & $\begin{aligned} & 6(40 \%) \\
& 5(56 \%) \\
& 2(67 \%) \\
& 7= \\
&758 \%)\end{aligned}$ \\
\hline Total .. & .. & 48 & $16(33 \%)$ & 49 & $25(51 \%)$ \\
\hline
\end{tabular}

TABLE II.-Leucopenia and Objective Improvement

\begin{tabular}{|c|c|c|c|c|c|}
\hline \multirow{2}{*}{\multicolumn{2}{|c|}{ Fall in W.B.C. }} & \multicolumn{2}{|c|}{ Nitrogen Mustard } & \multicolumn{2}{|c|}{ Cyclophosphamide } \\
\hline & & Total & Improved & Total & Improved \\
\hline $\begin{array}{l}60 \% \text { or more } \\
40 \%-59 \% \\
\text { Less than } 40 \%\end{array}$ & $\because$. & $\begin{array}{l}22 \\
15 \\
10 \\
\end{array}$ & $\begin{array}{l}6(27 \%) \\
6(40 \%) \\
3(33 \%) \\
\end{array}$ & $\begin{array}{r}26 \\
5 \\
9 \\
\end{array}$ & $\left.\begin{array}{l}13(50 \%) \\
43 \\
3\end{array}\right\}(50 \%)$ \\
\hline Total .. & $\ldots$ & 47 & $15(32 \%)$ & 40 & $20(50 \%)$ \\
\hline
\end{tabular}

inadequate records of $W$.B.C. due to error (4) or surgical intervention (3). 


\section{Toxic Effects}

Considerable and sometimes almost total loss of hair occurred in the cyclophosphamide-treated patients, but regrowth took place in those surviving long enough. There was no marked loss of hair in patients treated with nitrogen mustard.

Nausea or vomiting occurred in many patients after nitrogen mustard, but it was usually only slight, as all patients had heavy premedication.

Little gastro-intestinal upset occurred with cyclophosphamide, although a few patients complained of slight nausea and loss of appetite and two of slight diarrhoea. No premedication was necessary.

Leucopenia.-The course of cyclophosphamide had to be interrupted in seven patients because of leucopenia, but was completed later, and in another five patients the courses had to be terminated for the same reason at a dose of between 3.5 and 4.6 g. At one hospital all patients (49) had platelet counts on alternate days ; it was not necessary, however, to modify treatment because of a reduction of platelets, which tended to parallel the leucopenia but usually was less severe. No haemorrhagic complication occurred. There was no clear relation between the occurrence of objective improvement and the degree of leucopenia (Table II). The effect of the patient's body-weight on the degree of leucopenia occurring with these fixed cytotoxic drug regimens has also been studied and no definite relation was found.

\section{Respiratory Function}

In eight patients detailed tests of ventilatory function, lung volume, diffusing opacity, and compliance were carried out before and after intravenous cytotoxic therapy. No significant deterioration was found after treatment.

\section{Results of "Follow-up" Treatment}

There was no clear advantage to either agent as regards survival time ; neither did those improving on preliminary treatment do bettter than those who did not improve as regards survival time (Table III).

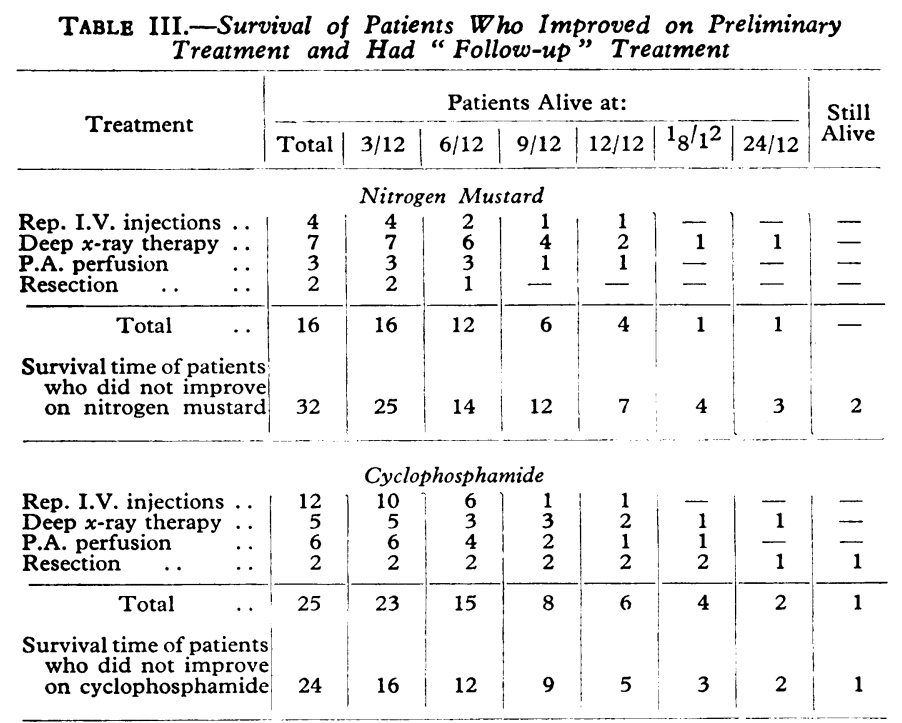

Of 56 patients who did not improve on preliminary treatment, 22 had further treatment later. Twelve had radiotherapy for various reasons; three of these survived one year, but none survived 18 months. Eight had surgical resection; five survived two years and three are still living.

\section{Discussion}

With these treatment regimens, cyclophosphamide provided a higher proportion of favourable responses than nitrogen mustard, and, although symptomatic improvement has not been taken into account in the assessment, we have the impression that it also provided symptomatic benefit more of ten.

Intravenous cyclophosphamide necessitates a more prolonged course than nitrogen mustard; but it causes less gastric upset and there is no severe reaction if any is given extravenouslyin marked contrast to nitrogen mustard, which has to be given into a fast-running drip to prevent thrombophlebitis and which causes a severe local reaction and often ulceration if there is any leak from the vein.

Since the end of the present series our patients have been treated with oral cyclophosphamide in doses of 200 to $400 \mathrm{mg}$. daily followed by a small maintenance dose. The results in this group suggest that cyclophosphamide is as effective orally as intravenously as regards remission rate and is as toxic as regards bone-marrow depression.

Loss of hair is a serious disadvantage of cyclophosphamide, especially to women, but this is usually reasonably well accepted if the patients know that regrowth will occur.

It has often been stated that nitrogen mustard does not prolong life in bronchial carcinoma (Bass, 1960). Grenville-Mathers and Trenchard (1964) were unable to show that patients treated with cyclophosphamide survived two months longer than a control group. Certainly it is very difficult to show any prolongation statistically because of the extreme variability of the natural history of the disease and because of the brevity of most of the remissions with treatment ; but in patients who experience rapid relief of severe bone pain, vena-caval obstruction, and severe dysphagia, with remission occasionally for periods of up to six months or more, it must surely be accepted that some prolongation of life has been achieved.

It has been suggested that regression occurs only in secondary gland masses and secondary deposits and not in the primary tumour. This has not been our experience, as many primary tumours have shown undoubted regression both radiologically and bronchoscopically.

Some authorities believe that worth-while remission can be obtained only if the dosage of the cytotoxic agent is sufficient to cause marked leucopenia. Our own findings (Table II) do not support this contention. Striking symptomatic and objective response not infrequently occurs after a few doses of cyclophosphamide or even one dose of nitrogen mustard, and we do not believe that the response of the tumour and that of the bonemarrow are closely related.

Flavell (1962) believes that any improvement with cytotoxic drugs of the nitrogen-mustard group is due to supportive antibiotics or steroids, but careful observation and assessment of the results of treatment in large numbers of patients without these supportive measures does not confirm this view. The patients in this series were treated with prednisone and Durabolin in view of the suggestion that these preparations safeguard the bone-marrow, and antibiotics were given only if they appeared to be essential.

The "follow-up" treatment was carried out to see whether $x$-ray therapy given to a tumour already in a state of partial remission from cytotoxic therapy resulted in unusually long remissions as compared with further intravenous and pulmonary-artery-perfusion therapy. After two years there were two survivors out of 12 patients who received follow-up radiotherapy, whereas 12 patients who had not improved on preliminary treatment had $x$-ray therapy later for various reasons and none of them survived 18 months. These groups are not strictly comparable and the numbers are small, so the difference may well be due to chance. Alternatively, a summation effect between the two treatments might be present or the response to the cytotoxic drugs could simply have occurred in tumours with parallel $x$-ray sensitivity. 
After more than two years there is one survivor out of four patients who underwent surgical resection after improving with preliminary treatment, whereas five out of eight having surgery without preliminary improvement survived two years and three are still alive. Again this difference could be pure chance. It could indicate that preliminary improvement on cytotoxic drugs was of no advantage or was harmful ; but it was probably at least in part due to the fact that improvement with cytotoxic drugs occurred in patients with more rapidly growing and metastasizing tumours, which were therefore less amenable to curative resection.

The pulmonary-artery-perfusion group was planned because of a remarkable result that occurred previously in one out of 25 patients treated in this way. He was a 52-year-old man who at thoracotomy was found to have an advanced oat-cell growth invading the main vessels. Three weeks later he was given one dose of $17.5 \mathrm{mg}$. of nitrogen mustard by drip into the right main pulmonary artery. The next day he felt much better, and five days later the chest $x$-ray picture showed marked reduction in the shadowing due to the growth. Two weeks later the $x$-ray appearance had returned to normal and bronchoscopy confirmed the apparent complete resolution of the neoplasm. Four further perfusions were carried out during the next year and he remained well and at work for this period. Early recurrence was first suspected after 16 months, and deep $x$-ray therapy was given after 20 months. He survived for two and a half years.

One patient in the present series treated by pulmonary-artery perfusion with cyclophosphamide survived over 18 months, but this was a case of squamous-cell carcinoma and may well have been naturally slow-growing. There were no other responses worthy of remark.

The place of cytotoxic-drug therapy in the treatment of carcinoma of the bronchus remains controversial. The present series suggests that in about $50 \%$ of patients the tumour will recede to some extent during high-dosage treatment with cyclophosphamide.

Poulsen's (1962, 1963) findings of a higher one-year survival rate in patients with operable squamous-cell carcinomas treated with pre-operative and post-operative cyclophosphamide than in a controlled group having surgery alone encourages further research on these lines in the early cases.
With advanced disease the remissions are usually short, ranging from two to six months, but often they are worth while from the point of view of relief of distressing symptoms. It remains to be seen whether better results can be obtained with maintenance therapy or the combination of two or more different agents, and whether, when combined with $x$-ray therapy, summation or sensitizing effects can be obtained.

\section{Summary}

Ninety-seven patients with bronchial carcinoma were treated with nitrogen mustard or cyclophosphamide. Of those treated with cyclophosphamide $51 \%$ responded favourably as judged by the objective evidence, compared with $33 \%$ of those receiving nitrogen mustard, but the limits of tolerance of nitrogenmustard dosage may not have been reached. "Follow-up" treatment of patients who had improved was carried out with $x$-ray therapy, further intravenous injections, or pulmonaryartery cytotoxic perfusion.

We are grateful to the surgeons, physicians, and general practitioners of the York/Harrogate Area whose patients were included in the series; and also to Dr. J. Nuttall and Dr. Joan Mallender, who supervised the $x$-ray therapy; to Dr. Mary Catterall and Dr. J. Stoker, who carried out the respiratory physiology studies at Leeds General Infirmary ; to the late Dr. G. Henry for help throughout ; to Dr. J. M. Simister for advice on the cytotoxic drugs ; and to Mr. Michael Curwen, of St. Bartholomew's Hospital, for much assistance and statistical advice; and to Mrs. Armitage and Mrs. Guest for the secretarial work.

\section{REFERENCES}

Bass, B. H. (1960). Brit. med. F., 1, 617.

Braun-Wotke, I. (1963). Wien. klin. W schr., 75, 52.

Flavell, G. (1962). Brit. med. f., 1, 284.

Grenville-Mathers, R., and Trenchard, H. J. (1964). Lancet, 2, 1200.

Hatch, H. B., Bradford, J. K., and Ochsner, A. (1956). F. Amer. med.

Ass., 160, 1129.
Kent, L., and Reh, E. P. (1950). Dis. Chest, 17, 190.

Levine, B., and Weisberger, A. S. (1955). Ann. intern. Med., 42, 1089.

Lynch, J. P., Ware, P. F., and Gaensler, E. A. (1950). Surgery, 27, 368. Poulsen, O. (1962). F. int. Coll. Surg., 37, 177.

(1963). Acta chir. scand., 125, 498.

Spear, P. W., and Patno, M. E. (1962). Cancer Chemother. Rep., 16, 413.

\footnotetext{
- Head of Cancer Chemotherapy Unit, Imperial Cancer Research Fund, Lincoln's Inn Fields, London.

t Senior Technician, Cancer Chemotherapy Unit, Imperial Cancer Research Fund, Lincoln's Inn Fields, London.

¥ Research Assistant, Cancer Chemotherapy Unit, Imperial Cancer Research Fund, Lincoln's Inn Fields, London.
}

formance in preventing homograft rejection has not been an unqualified success.

Thalidomide is known to be relatively non-toxic (Somers, 1960). If it also had immunosuppressive properties this would at once provide another aspect to explanations of its teratogenic action, and, at the same time, make it of considerable interest to those who seek to modify homograft rejection. To test whether it had any immunosuppressive properties its effect on the survival of mouse-skin homografts was examined. Mousestrain combinations with strong $\left(\mathrm{C}_{57} \mathrm{BL}-\mathrm{C}_{3} \mathrm{H} / \mathrm{He}\right)$ and with weaker $\left(\mathrm{A}-\mathrm{C}_{3} \mathrm{H} / \mathrm{He}\right)$ differences at the $\mathrm{H}-2$ histocompatibility locus were used.

In previous experiments (to be published) it was found possible to modify the antigenic character of skin grafts by in vitro treatment prior to transplantation; thus rejection was obtained of syngeneic skin grafts previously incubated with 